\title{
Effect of Electronic Reverse Auctions on Competition and Abnormally Low Bids in Public Construction Procurement
}

\author{
Tomáš HANÁK, Ivan MAROVIĆ, Nikša JAJAC
}

\begin{abstract}
The increasing complexity of construction projects imposes the need to address various aspects of project management in more detail. The success of a construction project depends on many variables and the process of supplier selection is certainly one of them. In recent years, the importance of electronic reverse auctions use in public sector construction procurement has been increasing, since they can bring substantial price savings. However, auctions are also criticized since they may result in the submission of abnormally low bids. This paper therefore aims to explore the impact of electronic reverse auctions on the competitive environment in public works contracts and on the occurrence of abnormally low bids. The results of quantitative research on Czech construction tenders revealed that the use of auctions decreases the number of bidders while increasing the probability of occurrence of abnormally low bids.
\end{abstract}

Keywords: abnormally low bid; competition; construction project management; electronic reverse auction; public procurement

\section{INTRODUCTION}

The use of electronic reverse auctions (e-RA) within the construction sector is seen as controversial due to ethical reasons, unsuitability of some products for auction, potential inadequate quality of delivery and submission of abnormally low bids by suppliers as well as other reasons. Inexperienced purchasing personnel and incorrect management decisions regarding the use of e-RA may cause significant losses and problems during the performance of public works contracts as well as afterwards when buildings and facilities are in operation. As the aspect of life cycle costs [1] gains in importance, due to increased energy consumption of buildings and other factors, more attention should be paid to the quality of the construction works delivered. As quality is related to bid prices [2], it is crucial to detect potential abnormally low bids (ALB) to prevent future delivery problems. This paper explores the effect of e-RA on the competition in public works tenders in relation to the frequency of ALB.

\section{BACKGROUND}

Over past decades, e-RA have become a useful electronic tool to select suppliers and award tenders in various industries for different products, services and works. They can be defined as online real-time bidding events between a purchasing institution (the buyer) and a group of pre-qualified suppliers competing among themselves in order to win the tender [3]. Buyers are motivated to use e-RA since they are associated with price savings [4], cycle time reduction [5], transparency of the tender procedure [6], elimination of geographical barriers [7], and enhanced efficiency of the purchasing process [4]. On the other hand, buyers must take into account that e-RA may also harm buyer-supplier relationships [3], require the purchase of hardware and software, cause a decrease in the quality of the delivery [5], and can be accompanied by low participation of bidders in the tender as some suppliers are not willing to participate in e-RA [6]. In this context, the findings of [8] show that the willingness to participate in e-bidding is strongly influenced by perceived barriers and benefits, costs, and security concerns.

The potential use of e-RA should be subject to a proper decision-making process, as auctions are not suitable for all purchase situations. Hawkins et al. [9] introduce an e-RA appropriateness model which can serve as a supporting tool for making an informed decision on e-RA adoption and use. The papers [10] or [11] can also be used in a similar way. In general, the following basic conditions should be met to handle e-RA appropriately: 1) the subject of the purchase can be clearly specified; 2) the quantity demanded is sufficiently attractive; 3 ) there is a sufficient supply base on the market; 4) suppliers are willing and prepared to participate in e-RA; and 5) the assumptions regarding potential price decrement in e-RA are reasonable (developed from [3] and [12]).

Although the use of e-RA is associated with various influencing variables, price savings are the main motivating factor for their use. As suppliers see other bids - or at least the best bid - offered in the tender, they have equal conditions and the opportunity to decrease their bids in order to win the contract. As the amount of price savings is associated with the number of bids in the tender [13], it is crucial to motivate the greatest possible number of potential suppliers to participate. In this context, authors in [14] argue that four bidders participating in e-RA already create a sufficient level of competition in the tender, supporting the conditions for a reasonable price decrement, which is promoted by new public management [15].

However, there is one important ethical question related to the use of auctions to decrease the purchase price: it is likely that as a consequence, suppliers will submit ALB more often in order to win the tender. ALB occur either inadvertently, as the consequence of incorrect cost estimates, or intentionally, as an attempt to stay in business [16]. Awarding the contract to suppliers who submitted ALB is risky, as the buyer may face cost and time overruns, a lower-quality delivery, or the inability of the supplier to complete the work during the delivery phase of the project.

It needs to be mentioned that the occurrence of ALB may also be supported by an incorrect cost estimate on the 
part of the buyer, who has to publish the "expected value" of the contract (EV). Authors in [17] report that the estimation of costs of large construction projects, such as transportation tunnels, is highly complex and challenging for public authorities during the feasibility stage. However, cost estimates are also more frequently inaccurate when they are made in later stages of a project and when they concern construction projects that are unique. Estimates of contract value are required by legal regulations [18] and, if applicable, can also be supported by relevant software tools based on project management approach enabling cost estimation [19].

ALB are nevertheless difficult to analyse, since their definition is not uniform. In some countries, ALB are defined as a deviation from the client's cost estimate or as a deviation from the average bid [20]. As they are difficult to detect, there have been suggestions to use statistical methods to determine bid "abnormality" [21] and a rank-and-compare algorithm was proposed by [22]. The key is how to set the right ALB width: if it is too narrow, it will cause rejection of bids that are actually competitive and valid [21].

In the Czech Republic, it is very challenging to detect ALB, since the applicable legislation does not define "abnormality" of bids in a mathematical way. The Act no. 137/2006 Coll. on Public Procurement [23], requires assessment of bid prices with regard to the subject of the contract by an evaluation committee. If any ALB are detected in this way, the evaluation committee must request a written explanation from the supplier; however, the law does not provide any objective guidelines for the detection.

Since e-RA have a significant effect on tender outcomes [24], the use of auctions within the construction sector deserves a more detailed examination focused on the competition in the tender and the occurrence of ALB. Important issues arising out of the conducted literature review are highlighted in the next chapter in the context of development of hypotheses.

As the current body of knowledge devoted to e-RA in the construction sector is limited, see studies [25] and [8] dealing with the perception of e-RA in project procurement from the point of view of construction contractors and with the willingness of construction organizations to participate in e-bidding, respectively, [21], and [26], this paper seeks to improve the understanding of e-RA in construction; specifically, it focuses on the potential of achieving sufficient competition in the tender and on the evaluation of undesirable occurrence of ALB in public works tenders.

\section{RESEARCH METHODOLOGY}

\subsection{Description of Area of Study and Research Sample}

This paper examines public works contracts in the Czech Republic; in particular, it deals with a set of tenders that have been processed both with and without the use of e-RA. Data on tenders not supported by e-RA were collected from the Bulletin of Public Procurement [27], an online portal operated by the Ministry of Regional Development of the Czech Republic, while data on tenders supported by e-RA were collected from the database of an e-RA system provider operating in the
Czech Republic. In total, 674 records on public tenders were collected (see Tab. 1). Information on the following variables was required for each record: subject of the tender, number of suppliers participating in the tender (NSup), estimated value of the contract (EV), and winning bid price (WBP). Any records that did not contain information on one or more of these variables were removed from the research sample. Furthermore, the research sample only included tenders with at least two assessed bids, since a tender with one bid or no bids submitted must be cancelled, according to applicable law. And finally, outliers in both categories (tenders with and without e-RA support) were removed by using boxplot. The resulting research sample, reduced in size to 387 records, was then examined further. A significantly higher difference between the sizes of initial and reduced research samples within tenders supported by e-RA is caused by a high frequency of missing variables in individual records.

Table 1 Basic characteristics of the research sample

\begin{tabular}{|l|c|c|}
\hline \multicolumn{1}{|c|}{ Category } & $\begin{array}{c}\text { Initial research } \\
\text { sample }\end{array}$ & $\begin{array}{c}\text { Reduced research } \\
\text { sample }\end{array}$ \\
\hline Supported by e-RA & 418 & 178 \\
\hline Not supported by e-RA & 248 & 209 \\
\hline Total & 674 & 387 \\
\hline
\end{tabular}

\subsection{Hypotheses and Methods}

Chapter 2 mentions several important aspects that arise in the context of e-RA use. One of them is that the use of e-RA can result in the reduction of the number of suppliers participating in the tender (as many suppliers are not willing to participate in e-RA). Accordingly, hypothesis $\mathrm{H} 1$ was formulated as follows:

$\mathrm{H} 1$ : The number of bidders participating in the tender is dependent on the use of e-RA.

Data are evaluated using a histogram.

Moreover, since high pressure on price forces suppliers to change their bid prices, it can be expected that the relative frequency of bid prices that could be considered as abnormally low will be higher in tenders supported by e-RA.

$\mathrm{H} 2$ : The occurrence of ALB is dependent on the use of e-RA.

The applicable Czech law [23] does not define ALB. With regard to hypothesis $\mathrm{H} 2$, ALB are therefore defined as the relative difference between EV and WBP equal to or higher than $40 \%$. In other words, ALB is detected if:

$$
\frac{E V-W B P}{E V} \geq 40 \%
$$

As the data consisted of two categorical independent variables, they were evaluated using a chi-square test with a $95 \%$ confidence interval. The evaluation only included values of winning bid prices in the individual tenders (the final bid prices of tender winners). Therefore, the potential occurrence of ALB in non-winning bids was not taken into consideration, because the research sample did not contain this data. 


\section{RESULTS AND DISCUSSION}

\subsection{Participations of Bidders in the Tender}

In relation to hypothesis $\mathrm{H} 1$, it was analysed whether the use of e-RA has an impact on the number of bidders in the tender. The data are shown in Fig. 1, where "e-RA S" represents tenders supported by e-RA and "e-RA NS" represents tenders that were not supported by e-RA.

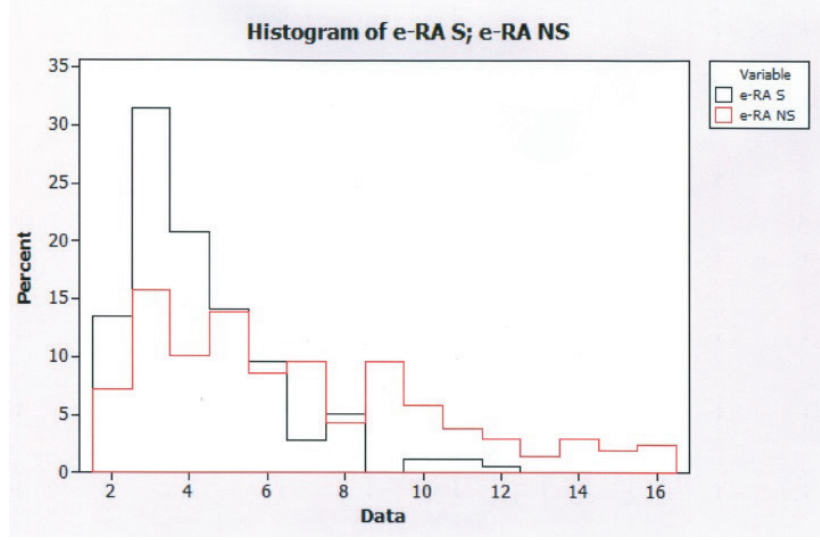

Figure 1 Participation of suppliers in tenders with and without e-RA support

The data clearly show that tenders supported by e-RA have lower numbers of bidders in comparison to tenders not supported by e-RA. In the category of tenders supported by e-RA, $65.7 \%$ of the tenders had two to four bidders, while in case of tenders without e-RA support it was only $32.5 \%$. Moreover, the highest number of bidders was 12 for e-RA S and 16 for e-RA NS. Nevertheless, competition in the tender should also be evaluated based on whether the number of bidders is sufficient, as authors in [14] argue that the participation of four bidders already creates favourable conditions for a reasonable price decrement. According to this measure, $44.9 \%$ of tenders supported by e-RA are classified as tenders with low competitive environment (three bidders or less). Based on these results, it can be argued that tenders supported by e-RA have considerably lower numbers of bidders than traditional tenders. Accordingly, hypothesis $\mathrm{H} 1$ is confirmed.

It should be noted that the number of bidders may depend on the specific market segment. The construction market is characterized by high product diversity, since public authorities demand delivery of works as dissimilar as transport infrastructure (roads, railways), buildings and facilities (offices, schools, hospitals) and engineering networks (water supply systems, sewerage). As the supply conditions on these individuals markets might be considerably different, future research should explore this aspect in more detail to determine which structures are not suitable for auctions with regard to achieving sufficient competition in the tenders. Such analysis may help to use e-RA in a more appropriate way, since they can be more successful when there is a higher level of competition on the supply market [28]. Therefore, estimates of the number of potential bidders competing in future tenders [29] should be of particular interest to buyers.

\subsection{Analysis of ALB Occurrence}

In order to evaluate the effect of e-RA use on the frequency of ALB occurrence in public works tenders, the data have been divided into relevant categories. The values of absolute frequency of tenders for public works contracts with and without ALB are presented in Tab. 2.

Table 2 Absolute frequency of tenders for public works contracts with and

\begin{tabular}{|l|c|c|c|}
\hline \multicolumn{1}{|c|}{ without ALB } \\
\hline Category & No ALB & ALB & Total \\
\hline Supported by e-RA & 145 & 33 & 178 \\
\hline Not supported by e-RA & 188 & 21 & 209 \\
\hline Total & 333 & 54 & 387 \\
\hline
\end{tabular}

The $\mathrm{p}$-value for the chi-square statistics of 5.773 with 1 degree of freedom is 0.016 . Since the $p$-value is $<0.05$, the null hypothesis on the independence of examined categorical variables is accepted; in other words, the frequency of ALB occurrence is not dependent on the use of e-RA. Accordingly, hypothesis $\mathrm{H} 2$ is rejected.

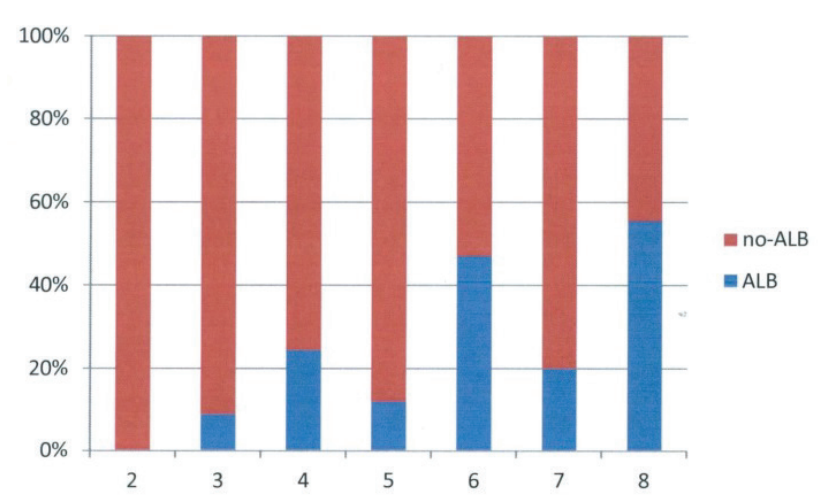

Figure 2 Representation of ALB within e-RA S with respect to the number of bidders

As the level of competition can be expressed by the number of bidders, it has also been evaluated whether the occurrence of ALB increases with increasing number of bidders for tenders supported by e-RA. Data indicating the relative representation of ALB in the research sample with respect to the number of bidders are shown in Figs. 2 and 3. Only tenders with up to eight bidders are included in the data, as the number of records within e-RA S above eight bidders is very small (only five tenders).

Fig. 2 suggests that there is a certain tendency to a higher probability of ALB occurrence with the increasing number of bidders. It is important to note that achieving lower prices in auctions may be at the expense of the quality of work delivered. A large disparity between expected value and winning bid price could mean that the contractor is making a loss, which he might want to compensate by using low quality materials or poor workmanship [25]. Scientific literature suggests an e-RA model with quality preference [30]; however, this model is mostly suitable for goods in multi-attribute auctions, not for the delivery of works. It is therefore crucial that the public authority specifies the subject of purchase clearly and in detail, ensures thorough inspection on the site during the whole period of execution of works, and also carefully checks whether the bids are abnormally low during the tender procedure to reduce the risk of future delivery problems. 


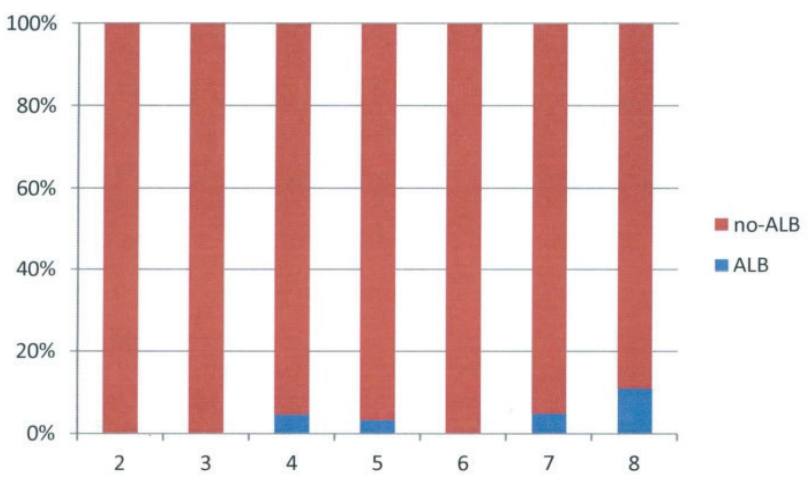

Figure 3 Representation of ALB within e-RA NS with respect to the number of bidders

Compared to the distribution of ALB within the e-RA $\mathrm{S}$ category, the occurrence of ALB within tenders not supported by e-RA with NSup $\leq 8$ is considerably smaller (Fig. 3). Bearing in mind that the occurrence of ALB is not dependent on the use of e-RA (see hypothesis H2), it is obvious that a larger proportion of ALB occurrence within e-RA NS appears if NSup $>8$. This result clearly shows that competition in auctions helps to decrease the purchase price even with a smaller number of suppliers participating in e-RA $S$ than in traditional procurement. It can therefore be concluded that with increasing number of participating suppliers, auctions contribute to price decrement, but on the other hand, the probability of ALB occurrence also increases.

Regarding the price decrement, buyers should monitor the development of project costs during its implementation thoroughly in order to avoid unfounded price increment. According to [31], cost control is ranked as the $5^{\text {th }}$ most important success aspect of construction project.

\section{RESEARCH IMPLICATIONS AND CONCLUSIONS}

Proper management of the public tender procedure is a key prerequisite for the success of the project. The complexity of construction projects increases the demand for efficient project management and makes public tender management even more difficult, as the buyers must pay attention not only to the performance of the works, but also to the preparation phase of the project and selection of suppliers.

This paper addresses one specific aspect of public sector construction procurement, namely the effect of electronic reverse auctions on competition and on the occurrence of abnormally low bids. This issue is important since awarding contracts to ineligible suppliers may cause significant problems during project delivery in terms of low quality of works and materials, time and cost overruns, or even the supplier's inability to perform the contract.

First, it was proven that electronic reverse auctions may cause a decrease in the number of suppliers participating in a given tender. On the other hand, when looking on the frequency of ALB occurrence in public works tenders, it seems that even with a lower number of bidders, it is possible to achieve higher price savings if e-RA are applied. Therefore, buyers should carefully estimate - with respect to the actual supply conditions on individual segments of the construction market - the potential number of suppliers participating in the tender to ensure a sufficiently competitive environment in the virtual auction hall.

Second, the research results showed that a higher level of competition in e-RA tenders contributes to the willingness of suppliers to submit ALB, usually motivated by fear of losing the contract. Hence, public authorities using e-RA should carefully check whether winning bids are abnormally low.

This research has two main limitations. First, the limited research sample did not make it possible to examine the potential effect of the type of work procured. It can be expected that there are different supply conditions on specific construction markets. Second, only the winning bid prices were examined, as the analysis did not contain data on bid prices submitted by all suppliers participating in the tenders. It would be interesting to examine how many bidders actually submit ALB in individual tenders.

Future research could focus on the creation of a more complex model taking into consideration additional aspects, such as the type of work, the volume of the contract or the attractiveness of individual buyers. The assessment of potential of financial savings that can be achieved through auctions also represents an interesting area of study. As price decrement is viewed as a crucial e-RA benefit, evaluation of the financial effect of e-RA use could potentially contribute to more informed decisions about the acceptance or rejection of electronic reverse auctions within construction project management and its procurement stage.

\section{Acknowledgment}

This paper was written with the support of grant project no. FAST-S-15-2944, "Effective Management of Processes in Civil Engineering II".

\section{REFERENCES}

[1] Korytárová, J. \& Hromádka, V. (2010). Building life cycle economic impacts. $4^{\text {th }}$ International Conference on Management and Service Science (MASS 2010) / Wuhan, 4 p. https://doi.org/10.1109//CMSS.2010.5577557

[2] Lin, C. \& Kong, D. (2015). The study of the relationship between bidding price and quality of public construction project in Taiwan. Journal of the Chinese Institute of Civil and Hydraulic Engineering, 27(2), 113-123.

[3] Beall, S., Carter, C., Carter, P., Germer, T., Hendrick, T., Jap, S. et al. (2003). The Role of Reverse Auctions in Strategic Sourcing, CAPS Research Report. http://lilgerry.com/beall2003ecom.pdf (15.3.2015)

[4] Emiliani, M. L. (2000). Business-to-business online auctions: Key issues for purchasing process improvement. Supply Chain Management, 5(4), 176-186. https://doi.org/10.1108/13598540010347299

[5] Hartley, J. L., Lane, M. D., \& Hong, Y. (2004). An Exploration of the Adoption of E-Auctions in Supply Management IEEE Transactions on Engineering Management, 51(2), 153-161.

[6] Caniëls, M. C. J. \& van Raaij, E. M. (2009). Do all suppliers dislike electronic reverse auctions? Journal of Purchasing and Supply Management, 15(1), 12-23. https://doi.org/10.1016/j.pursup.2008.10.003 
[7] Sashi, C. M. \& O'Leary, B. (2002). The role of Internet auctions in the expansion of $\mathrm{B} 2 \mathrm{~B}$ markets. Industrial Marketing Management, 31(2), 103-110. https://doi.org/10.1016/S0019-8501(01)00189-4

[8] Aibinu, A. A. \& Al-Lawati, A. M. (2010). Using PLS-SEM technique to model construction organizations' willingness to participate in e-bidding. Automation in Construction, 19(6), 714-724. https://doi.org/10.1016/j.autcon.2010.02.016

[9] Hawkins, T. G., Gravier, M. J., \& Wittmann, C. M. (2010). Enhancing reverse auction use theory: An exploratory study. Supply Chain Management, 15(1), 21-42. https://doi.org/10.1108/13598541011018102

[10] Kumar, S. \& Maher, M. (2008). Are the temptations of online reverse auctions appropriate for your business? Supply Chain Management: An International Journal, 13(4), 304-316. https://doi.org/10.1108/13598540810882198

[11] Mabert, V. A. \& Skeels, J. A. (2002). Internet reverse auctions: Valuable tool in experienced hands. Business Horizons, 45(4), 70-76. https://doi.org/10.1016/S0007-6813(02)00229-X

[12] Wamuziri, S. \& Abu-Shaaban, N. (2005). Potential of reverse auctions in construction procurement. Proceedings $21^{\text {st }}$ Annual ARCOM Conference, Association of Researchers in Construction Management, / London, 611619

[13] Sičáková-Beblavá, E., Šatníková, S., \& Klátik, P. (2011). Electronic auctions in public procurement: Theory and Practice in the Slovak Republic (Elektronické aukcie vo verejnom obstarávaní: teória a prax na Slovensku, in Slovak). Transparency International Slovensko. http://www.transparency.sk/wp-content/uploads/2010/01/ aukcie.vnutro.indd .pdf (8.4.2015)

[14] Wagner, S. M. \& Schwab, A. P. (2004). Setting the stage for successful electronic reverse auctions. Journal of Purchasing and Supply Management, 10(1), 11-26. https://doi.org/10.1016/j.pursup.2003.11.001

[15] Ružić, O., Golubić, H., Latin, M., \& Klopotan, I. (2014). Public Management. Tehnički glasnik, 8(4), 461-466.

[16] Gunduz, M. \& Karacan, V. (2009). Damage to Treasury: Abnormally Low Tenders in Public Construction Works. Journal of Legal Affairs and Dispute Resolution in Engineering and Construction, 1(3), 130-136. https://doi.org/10.1061/(ASCE)1943-4162(2009)1:3(130)

[17] Membah, J. \& Asa, E. (2015). Estimating cost for transportation tunnel projects: A systematic literature review. International Journal of Construction Management. 15(3), 196-218. https://doi.org/10.1080/15623599.2015.1067345

[18] Juszczyk, M., Leśniak, A., \& Zima, K. (2014). Design and Build system in polish public sector - case study. Conference proceedings of People, Buildings and Environment 2014 / Kromeriz, 3, 221-231.

[19] Vukomanovic, M., Radujkovic, M., \& Nahod, M. M. (2012). Managing Construction Projects through 4D Perspective: Gala2012 - Project Management Software. Proceedings of International Scientific Conference People, Buildings and Environment 2012 / Lednice, 2, 455-465.

[20] Megremis, A. (2014). Abnormally Low Tenders: Making Detection Objective. The International Construction Law Review, 31(4), 460-478.

[21] Ballesteros-Pérez, P., Skitmore, M., Pellicer, E., \& González-Cruz, M. C. (2015). Scoring rules and abnormally low bids criteria in construction tenders: a taxonomic review. Construction Management and Economics, 33(4), 259-278. https://doi.org/10.1080/01446193.2015.1059951

[22] Conti, P. L., De Giovanni, L., \& Naldi, M. (2012). A rankand-compare algorithm to detect abnormally low bids in procurement auctions. Electronic Commerce Research and Applications, 11(2), 192-203.

https://doi.org/10.1016/j.elerap.2011.12.008
[23] The Czech Republic. Act. no. 137/2006 Coll. on Public Procurement.

[24] Amelinckx, I., Muylle, S., \& Lievens, A. (2008). Extending electronic sourcing theory: An exploratory study of electronic reverse auction outcomes. Electronic Commerce Research and Applications, 7(1), 119-133. https://doi.org/10.1016/j.elerap.2007.11.003

[25] Wamurizi, S. (2009). Using electronic reverse auctions in project procurement: Perceptions of construction contractors. 25 th Annual ARCOM Conference, Nottingham, $167-176$.

[26] Hatipkarasulu, Y. \& Gill Jr., J. H. (2004). Identification of shareholder ethics and responsibilities in online reverse auctions for construction projects. Science and Engineering Ethics, 10(2), 283-288. https://doi.org/10.1007/s11948-004-0024-6

[27] Ministry of Regional Development of the Czech Republic. Bulletin of Public Procurement, online portal. http://www.vestnikverejnychzakazek.cz/

[28] Standaert, W., Muylle, S., \& Amelinckx, I. (2015). An empirical study of electronic reverse auction project outcomes. Electronic Commerce Research and Applications, 14(2), 81-94. https://doi.org/10.1016/j.elerap.2014.12.001

[29] Ballesteros-Pérez, P., Skitmore, M., Pellicer, E., \& Gutiérrez-Bahamondes, J. H. (2016). Improving the estimation of probability of bidder participation in procurement auctions. International Journal of Project Management, 34(2), 158-172. https://doi.org/10.1016/j.ijproman.2015.11.001

[30] Zhang, L. (2015). Reverse auction mechanism design with quality preference. $12^{\text {th }}$ International Conference on Service Systems and Service Management (ICSSSM 2015), Guangzhou, 5 p. https://doi.org/10.1109/ICSSSM.2015.7170286

[31] Varajão, J., Dominguez, C., Ribeiro, P., \& Paiva, A. (2014). Critical success aspects in project management: Similarities and differences between the construction and the software industry. Tehnicki Vjesnik, 21(3), 583-589.

\section{Contact information:}

Tomáš HANÁK, PhD, Associate Professor

Faculty of Civil Engineering, Brno University of Technology,

Veveři 95, 60200 Brno, Czech Republic,

E-mail: hanak.t@fce.vutbr.cz

Ivan MAROVIĆ, PhD, Assistant Professor

Faculty of Civil Engineering, University of Rijeka

Radmile Matejčić 3, 51000 Rijeka, Croatia

E-mail: ivan.marovic@gradri.uniri.hr

Nikša JAJAC, PhD, Associate Professor

Faculty of Civil Engineering, Architecture and Geodesy, University of Split Matice hrvatske 15, 21000 Split, Croatia

E-mail: njajac@gradst.hr 